\title{
Automotive Tire Pressure Tests Based on WSB-TPMS Applications
}

\author{
$\mathrm{Yi} \mathrm{Su}^{1, *}$ and Nacer Bellaloui ${ }^{2}$ \\ ${ }^{1}$ Automotive Technology, Wuxi Institute of Commerce, Wuxi 214153, China \\ ${ }^{2}$ Crop Genetics Research Unit, USDA-ARS, Stoneville, USA
}

\begin{abstract}
Indirect tire pressure monitoring system (WSB-TPMS) is an effective tool to measure and display the conduct of automobile tire pressure by monitoring and comparing the performance of automobile tires speed. It is not only timely and accurate delivery of tires for users pressure of real-time information to ensure driving comfort, but also abnormal tire pressure alarm, thereby alerting the user to exclude risks, to ensure driving safety. In this study, the principles of tire pressure monitoring system (TPMS) as well as WSB-TPMS systems are described. In particular, it is related to the calculation method for tire pressure and work steps of WSB-TPMS system information for a more systematic analysis. Next, the WSB-TPMS system application performance in the automotive tire pressure tests were discussed from the temperature testing, pressure testing and power consumption test, etc. WSB-TPMS system, with accuracy, reliability and stability in these areas, the system can be widely used for automobile tire pressure testing. Research around the car to test the tire pressure unfolds, demonstrating the monitoring function WSB-TPMS system, and thus have a strong practical significance.
\end{abstract}

Keywords: Indirect tire pressure monitoring system, Tire pressure test, WSB-TPMS.

\section{INTRODUCTION}

Car tire pressure testing is one of important security configuration items, which can effectively reduce the uneven force caused by a puncture accident. However, since many of the current system of ordinary models do not include equipment tire pressure testing system, so the ordinary motorists did not have sufficient knowledge of tire pressure testing, and routine maintenance of the car did not attach great importance to the work [1]. Tire pressure too low or too high is not conducive to play car performance. When the tire pressure is too high, the area of the tire force (effective contact area with the road surface) will be small. This will reduce the tire pressure on the one hand and, on the other hand will reduce the tire grip, which may cause the car bit slip in the process of moving, and even increase the risk of accidents. In the process of driving a vehicle, people's own direct experience of excessive tire inflation, poor road conditions on passing lots, vibration sense cars will be relatively more pronounced, thus affecting driving comfort. And when tire pressure is too low, the car's axle is damaged, and through ups and downs road will also damage site and other important parts of cars. Therefore, the detection and control of the tire pressure during car driving increase safety, comfort and car use age and thus, has an important role. For this reason, many car brands will be specially designed and equipped with the automotive tire pressure measurement system.

*Address correspondence to this author at Automotive Technology, Wuxi Institute of Commerce, Wuxi 214153, China;

Tel: +8613829101765; E-mail: suyi@126.com
The so-called tire pressure with measurement system (tire pressure monitoring system, abbreviated as TPMS) refers to driving (use) an automatic car tire pressure test system, and tire pressure close to and over the upper and lower limit alarm, ensuring the safety of the car use. Tire pressure test system can be divided into direct tire pressure measurement system (Direct Tire Pressure Monitoring System, DTPMS) and indirect tire pressure measurement system (Wheel-Speed Based TPMS, referred WSB). Next, the paper will test the system of indirect tire pressure in a car tire stress test application to discuss issues, hoping to apply that indirect tire pressure test system has some role [2].

\section{TPMS AND WSB-TPMS PRINCIPLES}

TPMS is a system used for testing the car's automatic tire pressure in travel. It can be close to hand over the upper and lower limit alarm tire pressure, to ensure the safety of motor vehicles. When the leak occurred in the car in traffic, and the tires pressure is lower than the load, tire pressure drops. The tire pressure monitoring system can be determined by the poor condition of the tire pressure occurs between the rotation speed comparison tires and locking tires. In actual use, the tire pressure monitoring system can be divided into direct tire pressure measurement system (Direct Tire Pressure Monitoring System, DTPMS) and indirect tire pressure measurement system (Wheel-Speed Based TPMS, referred WSB). Their works are different. DTPMS is operational process requires the car to have the original valve with a valve sensor instead. Thus, with a valve sensor sensing can be carried out through which the temperature sensor chip car tires, tire pressure, etc. can be calculated. It will be perceived 


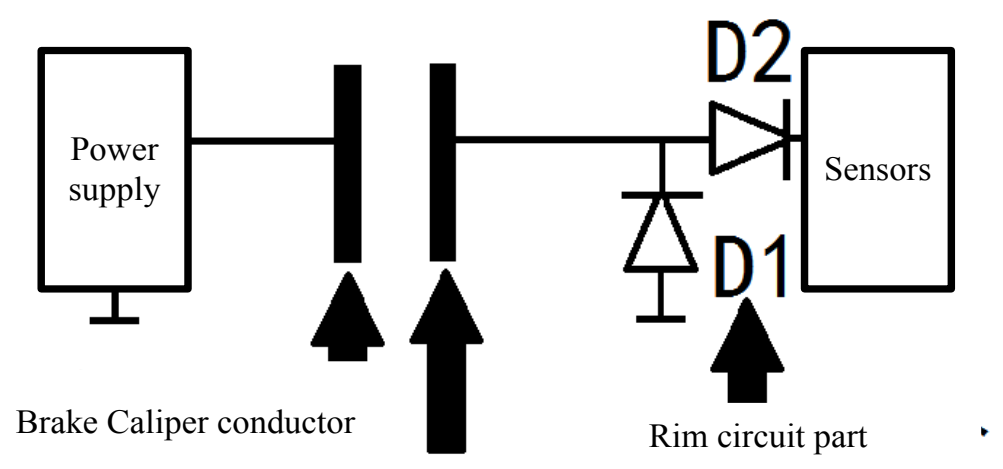

Valve

Fig. (1). The principle of indirect TPMS figure.

transmitting information obtained in the form of the control system to DTPMS RF signal within the receiver. DTPMS can not only sense the motion state of automobile tires tire pressure and temperature, but also can sense changes of the tire pressure and temperature under stationary state body. DTPMS has now been more widely used [3]. Most domestic cars and imported cars are using a small part of such a tire pressure monitoring system. DTPMS corresponding system is indirect tire pressure measurement system (WSB-TPMS), which works with DTPMS. They are apparently different. The next section will be devoted to this.

Indirect tire pressure test system, WSB-TPMS, works with the direct tire pressure measurement system, DTPMS, although the pressure signal from the transmission are in different ways. Specifically, WSB-TPMS sensor does not carry the valve body so the tire pressure, temperature, and other information is obtained through the toughness. Relatively, in order to obtain this information, the system would be to obtain the vehicle body by way of a non-contact tire pressure. Thus, WSB-TPMS operation needs to use the car's ABS system (Anti-locked Braking System, which is a kind of anti-skid, anti-lock etc. automobile safety control system) carried to get the speed of the wheel through speed sensor body of each tire. And tire pressure monitored by comparing the difference in speed and tires as well as their timing variations. As shown in Fig. (1), WSB-TPMS works in three phases:

(1) ABS speed sensor system to capture car speed. When the vehicle is running in a pressure increase or decrease, the effective radius of the tire is increased or reduced accordingly, which will affect the speed of the tire. The speed of tire pressure increase is lower than the normal rotational speed, and the speed of the tire pressure reduction is higher than normal tires. ABS speed sensor system will be passed to the ABS system control unit after capturing this information.

(2) ABS system control unit to analyze the speed of the received information. ABS system control a unit through a particular algorithm, analyze wheel speed indicator parameters, and the results will be passed to the alarm system [4].

ABS control unit will use an algorithm to calculate the received message as follow:
$n=\frac{\omega_{F L} \bullet \omega_{R R}}{\omega_{F R} \bullet \omega_{R L}}$

In formula (1), $\mathrm{n}$ represents the rate of the tire rotation (in the interval $[0,1]) . \omega$ indicates the rotational speed of the tire body. $F / R$ : Front / rear tires, $R / L$ : left / right tires.

According to the principles of automobile kinematics, car tires speed is calculated according to the following formula:

$\omega=\frac{v_{F L}}{\gamma_{F L}}\left(1-S_{F L}\right) \cos \alpha_{F L}$

In formula (2), $\omega$ represents the rotational body speed of the tire. $v_{F L}$ indicates the speed of the car before the tire row. $\gamma_{F L}$ represents the effective radius of the vehicle tires. $\alpha_{F L}$ the tire angle of slide, and $S_{F L}$ represents a rotation of the tire slip ratio (in the interval $[0,1]$ ).

Under normal circumstances, a very small car tire slip angle, is negligible. Therefore, it is assumed that $\cos \alpha_{F L}=1$, and also may be assumed that the sliding angle of about the same axis and the slip ratio of the tire both are same. Then, the relationship between the effective radius of each tire can be used as shown in formula (1) of the wheel speed. The equation used to express the relationship between the pressure of the tires according to the relationship can be expressed as follows, namely:

$n=\frac{\omega_{F L} \bullet \omega_{R R}}{\omega_{F R} \bullet \omega_{R L}} \approx \frac{\gamma_{F R} \bullet \gamma_{R L}}{\gamma_{F L} \bullet \gamma_{R R}}$

In formula (3), the meaning of each parameter is the same as formula (1), (2) and (3). The alarm system alerts the police. When the ABS system control unit through the analysis of information and control indicates abnormalities (higher or lower than the control indicators), alarm system warning light will illuminate to warn audible car maintenance personnel or the driver [5].

There are three kinds of WSB-TPMS measurement ranges: there is only one vehicle tire leak, or there are two leaks on the angular position of the body, or there are three tires 

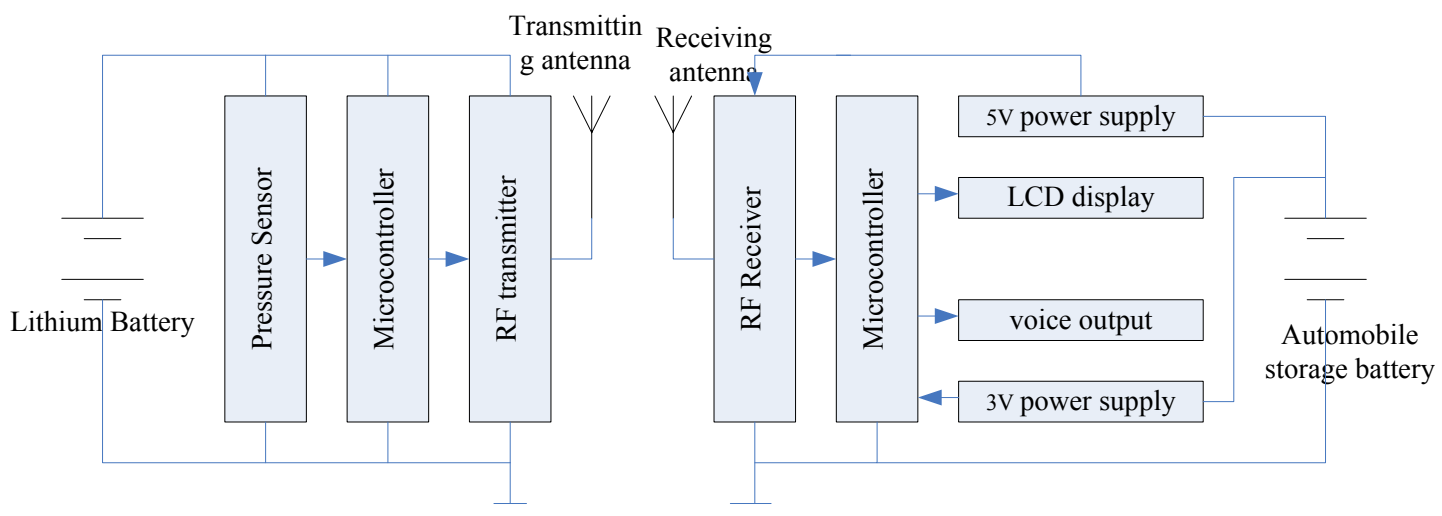

Fig. (2). WSB - TPMS system work framework.

(any position) leak. These three kinds of anomalies in the tires occur when the vehicle tire rotation rate (n) is less than 1 , using the ABS system analysis and alert by WSB-TPMS. With WSB-TPMS monitoring the situation for some flat tire can not be done effectively, for example, in an axle there is leakage with two tires at the same time, there is leakage in two tires on the same side of the body at the same time, and four tires at the same time leak or when the vehicle speed exceeds $100 \mathrm{mph}$. The WSB-TPMS will fail to monitor these leaks effectively and prompt the driver.

\section{WSB-TPMS APPLICATIONS IN THE AUTOMO- TIVE TIRE PRESSURE TESTS}

In the course of the study, WSB-TPMS tire pressure is applied to the test, which will involve temperature, power consumption, pressure and other projects. Next, in this paper these three items were included as parameters for test analysis. In the test, WSB-TPMS system will follow the framework shown in Fig. (2) for testing operations.

The temperature range of this experiment is $40^{\circ} \mathrm{C} \sim$ $150^{\circ} \mathrm{C}$, and the temperature value can be set to a certain constant temperature. Testing the temperature with a resolution of $1{ }^{\circ} \mathrm{C}$, namely temperature changes by more than $1{ }^{\circ} \mathrm{C}$ will be recognized when the otherwise indistinguishable, implementation process as follows:

(1) WSB - TPMS is equipped with batteries, so that all parts of the system are in operation. At the same time, open the ABS system. Module for receiving a signal and a tire pressure information transmission module is connected to the power supply.

(2) The transmission module of the tire pressure information is placed in a thermostat to adjust and set the temperature. While the received signal module is placed next to the thermostat in order to read.

(3) Record the experimental data and statistics out in tabular form.

As shown in Table 1, the measured temperature of the test data with the variation of oven temperature set point changes:

From the detected temperature record in Table 1, it can be found that the temperature detection effect of WSBTPMS is more accurate, especially within the range of $-14^{\circ} \mathrm{C}$ to $80{ }^{\circ} \mathrm{C}$. The receiver display temperature readings and thermostat module are exactly the same, without deviation. While beyond this temperature range, the majority of test temperature values are also consistent with the oven temperature values. This proves that the WSB-TPMS used within the tire body temperature monitoring is reliable [6].

The pressure test procedure consists of the following three steps:

(1) Start monitoring equipment: Install the battery for signal transmission module, display module for receiving, WSB-TPMS system and the ABS system connected to an external power source.

(2) The signal transmission module placed in a pressure vessel testing and closed pressure vessel. Meanwhile, the pressure signal reception display module is placed next to the pressure vessel.

(3) Adjusting the pressure of the pressure vessel, to begin the experiment and record the statistics.

As shown in Table 2, the test pressure data obtained in this experiment is with changes in the pressure of the pressure vessel and shows the same trend changes.

As can be seen from Table 2, test data trend is consistent with the normal data in the data field showing the pressure vessel and test vehicle tire pressure read on the display. Although there is an error between these two types of data, yet the error is a very small value gap between each set of data within $0.5 \mathrm{kPa}$. Error sources may be a long time run pressure vessel, and some loose parts may cause the display lag. It also may be due to the presence of air pressure in the pressure vessel causing the reading changes. Tests also may be due to the resolution of the sensor used to accept the result of inappropriate reading i.e. the display module errors. Since the error is extremely small, almost negligible, so the test is a powerful illustration of the WSB-TPMS tire pressure system monitoring carried out, and is considered accurate and credible.

WSB - TPMS system in the process of tire pressure test consumes power which not only affects the life of the system itself, but also affect the accuracy of the test results. So it is necessary to carry out tests to verify its power consumption. The operation of WSB - TPMS systems need to consume battery. If the battery runs out in the process of car use, its 
Table 1. Temperature test data.

\begin{tabular}{|c|c|c|c|c|c|c|c|c|c|}
\hline Oven Temperature Value $\left({ }^{\circ} \mathrm{C}\right)$ & -30 & -28 & -26 & -24 & -22 & -20 & -18 & -16 & -14 \\
\hline Temperature value of the received signal modules displayed $\left({ }^{\circ} \mathrm{C}\right)$ & -30 & -30 & -28 & -25 & -22 & -20 & -19 & -17 & -14 \\
\hline Oven temperature value $\left({ }^{\circ} \mathrm{C}\right)$ & -12 & -10 & -8 & -6 & -4 & -2 & 0 & 3 & 6 \\
\hline Temperature value of the received signal modules displayed $\left({ }^{\circ} \mathrm{C}\right)$ & -12 & -10 & -7 & -6 & -4 & -2 & 0 & 3 & 6 \\
\hline Oven temperature value $\left({ }^{\circ} \mathrm{C}\right)$ & 9 & 12 & 15 & 18 & 21 & 24 & 27 & 30 & 33 \\
\hline Temperature value of the received signal modules displayed $\left({ }^{\circ} \mathrm{C}\right)$ & 9 & 12 & 15 & 18 & 21 & 24 & 27 & 30 & 33 \\
\hline Oven temperature value $\left({ }^{\circ} \mathrm{C}\right)$ & 36 & 39 & 42 & 45 & 48 & 51 & 54 & 57 & 60 \\
\hline Temperature value of the received signal modules displayed $\left({ }^{\circ} \mathrm{C}\right)$ & 36 & 39 & 42 & 45 & 48 & 51 & 54 & 57 & 60 \\
\hline Oven temperature value $\left({ }^{\circ} \mathrm{C}\right)$ & 63 & 65 & 68 & 71 & 74 & 77 & 80 & 83 & 86 \\
\hline Temperature value of the received signal modules displayed $\left({ }^{\circ} \mathrm{C}\right)$ & 63 & 65 & 68 & 71 & 74 & 77 & 80 & 84 & 86 \\
\hline Oven temperature value $\left({ }^{\circ} \mathrm{C}\right)$ & 89 & 92 & 95 & 98 & 100 & & & & \\
\hline Temperature value of the received signal modules displayed $\left({ }^{\circ} \mathrm{C}\right)$ & 90 & 92 & 96 & 99 & 101 & & & & \\
\hline
\end{tabular}

Table 2. Pressure test data.

\begin{tabular}{|c|c|c|c|c|c|c|c|c|}
\hline Pressure Vessel Pressure Readings (kPa) & 100.0 & 115.2 & 135.7 & 157.2 & 176.8 & 195.9 & 214.4 & 233.9 \\
\hline Pressure signal receiver pressure readings $(\mathrm{kPa})$ & 100.0 & 115.1 & 135.8 & 156.9 & 176.6 & 196.1 & 214.2 & 233.7 \\
\hline Pressure vessel pressure readings $(\mathrm{kPa})$ & 255.0 & 274.9 & 295.1 & 316.1 & 324.7 & 345.1 & 366.2 & 380.0 \\
\hline Pressure signal receiver pressure readings $(\mathrm{kPa})$ & 249.8 & 274.5 & 295.0 & 316.2 & 324.5 & 344.9 & 366.3 & 379.8 \\
\hline
\end{tabular}

Table 3. Tire measuring the emission module state of current consumption.

\begin{tabular}{|c|c|c|}
\hline Measuring Module State & Working Current (ma) & Working Time (s) \\
\hline \hline Measuring state & 0.012 & 58.33 \\
\hline Dormant state & 2.5 & $0.015 \times 20$ \\
\hline Emission state & 7.3 & 0.026 \\
\hline
\end{tabular}

function will be hard to play, and may cause interference to the driver, thus affecting the driving safety and comfort. Therefore, the power consumption of WSB-TPMS system experimental test is very necessary [7].

In WSB-TPMS system, factors influencing the energy consumption include signal transmission frequencies and sampling rates of ABS. For example, if the sampling rate of ABS system is at a high level, its power consumption will reach several milli amperes per second $(\mathrm{mA})$. And when its sampling rate is low, power consumption is only ten microamperes (uA). Therefore, when use WSB-TPMS tire pressure system tested, minimize the use of high-frequency clock. In this study, the ABS system microcontroller clock is set to $1 \mathrm{MHz}$, and the measurement interval is set to $3 \mathrm{~s}$. When the tire pressure exceeds, the upper and lower temperature exceeds the upper or lower limit, the microcontroller ABS system shall transmit an alarm. After measuring the current, consumption of the measurement modules are displayed in different states as shown in Table 3 .
It can be seen that WSB-TPMS system can work for not less than 2 years. Since the system will only work in the process of the vehicle, and the vehicle in the still state does not produce energy computation, therefore the system must have more than the actual useful life of 2 years. This ensures the stability of the system, thereby reducing the energy consumption of the system which is generated due to loss of energy [8]. For example, WSB-TPMS system for automobile tire pressure monitoring, is stable and reliable; it can ensure the risk of energy depletion for a user over an extended period.

WSB-TPMS system is effective as a real-time monitor and real-time feedback for automobile tire pressure. The user can not only ensure the comfort of the car, they can also use the user's security alerts to provide timely and reliable information. Therefore, the system can be widely used as tire pressure test. 


\section{CONCLUSION}

This study through WSB-TPMS systems in the automotive tire pressure monitoring process temperature monitoring capabilities, pressure monitoring capability and power status test to prove the accuracy, reliability and stability of the system. In fact, WSB-TPMS system can effectively provide real-time monitor and real-time feedback for automobile tire pressure. The user can not only ensure the comfort of the car, they can also use the user's security alerts to provide timely and reliable information. The system is thus highly recommended for use as tire pressure test.

\section{CONFLICT OF INTEREST}

The authors confirm that this article content has no conflict of interest.

\section{ACKNOWLEDGEMENTS}

Declared none.

\section{REFERENCES}

[1] G. B. Tao and L. Pang, "Direct tire pressure monitoring system design", Chongqing University, vol. 3, p. 52, 2011.

[2] F. Zhang, X. P. Li, and S. L. Fu, "Tire pressure monitoring system in the application of the vehicle tire safety", vol. 4, p. 49, 2012.

[3] L. W. Tong, T. Yu, and Y. Pan, "Tire pressure monitoring system", Micro Computer Information, vol. 22, no. 7, p. 112, 2011.

[4] Q. Zhao and J. F. Shen, "Tire pressure monitoring system", Hefel University of Technology (Natural Science Edition), vol. 30, no. 3, p. 312, 2011.

[5] G. J. Oyewole, and A. E. Oluleye, and E.O. Oyetunji, "Minimizing maximum stretch on a single machine with release dates", Advances in Industrial Engineering and Management, vol. 3, no. 1, pp. 1-12, 2014.

[6] J. Wang, Z. L. Liu, and Y. Chen, "Comparative Analysis of Economic Efficiency of Grain Storage by Solar Absorption Refrigeration", AISS: Advances in Information Sciences and Service Sciences, vol. 4, no. 14, pp. 341-348, 2012.

[7] X. J. Gao, G. L. Wang, and S. Z. Ying, "The development trend of tire pressure monitoring system", Tire industry, vol. 27 , no. 8 , pp. 45, 2012.

[8] C. G. Yan, "TPMS sensor module dedicated technical analysis", Electronic Design \& Application, vol. 3, no. 11, p. 26, 2012.

Received: September 16, 2014

Revised: December 23, 2014

Accepted: December 31, 2014

(C) Su and Bellaloui; Licensee Bentham Open.

This is an open access article licensed under the terms of the Creative Commons Attribution Non-Commercial License (http://creativecommons.org/licenses/by-nc/4.0/) which permits unrestricted, non-commercial use, distribution and reproduction in any medium, provided the work is properly cited. 